\title{
The Digital Materiality of Digitized Manuscripts
}

A strange paradox has crept into philological work of all kinds of fields, such as classics, sinology, Islamic studies, medieval studies, and many others. Scholars have been so eager to take advantage of digitized manuscripts, that Wido van Peursen, a biblical scholar, notes: "now that the digital object has become available, who will ever go back to the 'real' manuscript?"1 This in itself may already be a paradox, suggesting that the more our research focusses on the manuscript world, the more our work takes place in the digital world. However, the paradox I have in mind is about what happens next. For, when it is time to disclose our sources, we refer to the actual, material manuscript and seem to forget we ever looked at digital images. Can we identify the digital surrogate so strongly with the material artifact? Or should we say that the two have nothing to do with each other? After a discussion of how digital resources are being incorporated in a paper-based scholarly discourse, I shall discuss these two positions. I shall conclude that both are untenable. Instead, for evaluating the use of digitized manuscripts we need to describe their 'digital materiality'. I introduce ten categories that can give shape to such a description and I end with a forceful call to include such a description in our publications, when we have made use of digitized manuscripts. Disclosing the use of a digital surrogate, instead of pretending like we accessed the material artifact, should become part of sound, scholarly conduct.

It is generally understood that we are transitioning from a print world to a digital world, as explained in the previous chapter. Our own humanities fields are good examples of this. Publications in our subjects have a long shelf life and we therefore often require books and articles that appeared before the advent of digital publishing and only appeared in print. Yet, almost all currently active

1 Peursen, W. van. "Text Comparison and Digital Creativity: An Introduction." pp. 1-30 in Text Comparison and Digital Creativity, edited by W. van Peursen, E.D. Thoutenhoofd, and A. van der Weel. Leiden: Brill, 2010, p. 10. 
peer-reviewed journals publish their articles digitally. ${ }^{2}$ The rather obvious answer to bridge the gap has been to digitize relevant print resources. Let us, before we proceed, arrive at precise definitions surrounding digitization. The terms 'digital' and 'digitized' are adjectives denoting the state an object is in. Digital print sources are printed works that are now digitally encoded as fulltext, meaning that you can search through the contents, select it, and manipulate it (with limitations). We encounter them chiefly in two different flavors: either as plain text or as PDFS matching the lay-out and formatting as the print source. In the latter case, the file is almost certainly coming from the publisher. Digitized sources are photos or scans of pages of a print source. They can be a folder with as many image files as there are pages, or a PDF combining all images. The model used by platforms such as JSTOR, in which you see a scanned image of an article while still being able to select the text, is a combination of a digitized layer (the image) and a digital layer (the text). I shall use 'digital surrogate', 'digital photo', and 'digitized manuscript' more or less synonymously. By this I mean a collection of images of actual pages or page-spreads of a manuscript work. The qualification 'surrogate' is important, in order to emphasis the derivative nature of a photo which can only stand in for the original item in a limited manner, as will be amply discussed. Lastly, I frequently use 'digital repository', by which I mean a collection of either digital or digitized files, or a combination thereof, usually offered as one whole through a single website. In the literature, especially among librarians and archivists, it is often called a 'digital library', but I wish to forego a too careless identification of such digital resources with a brick and mortar library.

Four benefits of using digital repositories are generally mentioned. Using digital and digitized sources will speed things up, as one does not have to go to a library, collect, request, or recall all the necessary books and journals, and either photocopy them or keep extensive notes. It will, in addition, provide access to resources that are otherwise hard to get. Especially studying manuscripts benefit from digitization in this regard, as each is unique and can therefore only be accessed in one place on Earth, usually in a library with strict rules regarding their handling. Next to these two aspects of access on the item level, there is also a perceived benefit of being able to dig within a source directly to the desired passage. This is especially true for digitized sources of which the contents are fully searchable. Lastly, and more wishfully than actually so, it is

2 Collins, E., and M. Jubb. "How Do Researchers in the Humanities Use Information Resources?" pp. 176-87 in Liber Quarterly 21, no. 2 (2012), p. 177. 
said that digital repositories can open up new avenues of research, by allowing entirely new research questions, methods, and ways of publishing results. ${ }^{3}$

Consistently, however, it is print or manuscript sources that are cited by scholars, even if they used a digital surrogate. It does not matter if a scholars engages with a digital or digitized source, nor whether the source is originally an article, book, archival document, manuscript, or some other source from the manuscript or print world. ${ }^{4} \mathrm{~A}$ number of reasons can be identified.

Print is immutable, whereas digital is mutable. Once ink has formed a shape on paper, it is exceedingly hard to forge that letter into the shape of another letter. To do this for a whole sequence is near impossible. Printed works principally derive from their printing press, where their pages have been typeset. Thus, each item is an exact replica of another item, and in itself only offers the privilege to be read. It itself cannot be used to create another copy; only the original printing press can. Digital works, however, can themselves be changed at will and be replicated and disseminated in that new state. Access to them necessarily implies reading and writing privileges. An extreme example are entries for Wikipedia, whose contents undergo a process of change from moment to moment as each user is not only allowed to read it but also to fundamentally change it. Citing and critiquing a digital source becomes fraud, as by the time a reader compares the digital source, it might have changed and it will look as though the author who is giving the critique is doing so unwarranted. Scholarship needs fixed points of reference, which print can give and digital cannot.

Closely related is the reason that a printed work is much more self-reliant than a digital work. No electricity is needed, nor an internet connection, operating system, plug-ins, etcetera. Furthermore, the physical devices to store digital data, such as CD-ROMs and hard drives, generally have a life span as low as a few years, which is laughably short compared to printed works that are still functional after hundreds of years. This makes it seem that a printed work is more robust and future proof. Indeed, it is not hard to come up with

3 Collins, E., M.E. Bulger, and E.T. Meyer. "Discipline Matters: Technology Use in the Humanities." pp. 76-92 in Arts \& Humanities in Higher Education 11, no. 1-2 (2011), p. 81; Rimmer, J., C. Warwick, A. Blandford, J. Gow, and G. Buchanan. "An Examination of the Physical and the Digital Qualities of Humanities Research." pp. 1374-1392 in Information Processing and Management 44 (2008), p. 1375; Nichols, S.G., and N.R. Altschul. "Digital Philology: A Journal of Medieval Cultures." pp. 1-2 in Digital Philology: A Journal of Medieval Cultures 1, no. 1 (2012), p. 1.

4 Robinson, P. "Current Issues in Making Digital Editions of Medieval Texts—or, Do Electronic Scholarly Editions Have a Future?” Digital Medievalist 1 (2005); Collins, E., and M. Jubb. “How Do Researchers ...”, p. 182; Rimmer, J., et al., p. 1378; Collins, E., et al. “Discipline Matters”, p. 81. 
examples of resources once digitized and digitalized with great effort, which have already been rendered useless. ${ }^{5}$ Scholarship needs stability in its data, for otherwise the research is not replicable. This is something print can give and digital does not.

This brings us to curation, which can be wanting for digital works. It seems that most digitization efforts, turning manuscript and print sources into a digital surrogate, are project based. This means that once the project is over, the money dries up and the collection is no longer maintained. Meanwhile, the digital environment is one for which maintenance is crucial, as hardware and software need to be upgraded regularly. Printed sources require less curation, and for the part that they do, they are in the comfortable environment of a library which takes a programmatic approach to maintaining its holdings.

Digitized works are not cheap. They are most often accessed on a subscription model, in which the user or library does not buy ownership of the digital file, but buys access to it. Commercial vendors have stepped into this market, which often enforce legal limits to usage far beyond the protection of printed works. The rights of a scholar to retain a private copy are purposely pushed into a grey area. ${ }^{6}$ Libraries actively work against their users in this regard, for example by limiting the total number of scans someone is allowed to make. It is unclear how this will develop in the coming years. Indeed, this commercial and legal issue is highlighted by many scholars as one of the greatest challenges. ${ }^{7}$ Print, on the other hand, has worked out these issues long ago and we know what to aspect from it.

Digitization, further, regularly gives the impression of being complete. However, those who dig deep to find a particular edition of a work purported to be included in the Google Books or Microsoft Digitization projects, will often find that they are out of luck. It is likely that only one edition of a printed work is digitized, which may still be of use in the initial research phase but becomes unusable in the writing phase when it is often times crucial to cite a

5 Rimmer, J., et al., p. 1377.

6 Besek., J.M., et al., "Digital Preservation and Copyright: An International Study," pp. 104-111 in The International Journal of Digital Curation, vol. 2, no. 3 (2008).

7 Muri, A. "The Grub Street Project: Imagining Futures in Scholarly Editing." pp. 15-26 in Online Humanities Scholarship: The Shape of Things to Come, edited by J. McGann. Houston: Connexions, 2010; McGann, J. A New Republic of Letters: Memory and Scholarship in the Age of Digital Reproduction. Cambridge Mass.: Harvard University Press, 2014, pp. 20, 133; Rimmer, J., et al., p. 1387; Prescott, A. "Consumers, Creators or Commentators? Problems of Audience and Mission in the Digital Humanities." pp. 61-75 in Arts \& Humanities in Higher Education 11, no. 1-2 (2011), p. 65 . 
first or most recent edition. The user is forced to abandon the digitized work in favor of the printed work.

Lastly, then, it also comes down to perceived authority. If a certain printed edition is a standard reference point, scholars are inclined to give a similar reference rather than admitting they used a digital surrogate of this standard edition. An important aspect of the diminished authority of digital surrogates is their accessibility. Even though digitized works are far more accessible, they are so in a siloed manner. As Jerome McGann, scholar of English studies, argues, such a digitized work "lacks the professional infrastructure that the scholarly book possesses by virtue of the mature social network in which it is located." ${ }^{\prime 8}$ He goes on to say that: ${ }^{9}$

Internet ecology at present is volatile and promiscuous, it encourages individual initiatives and "just-in-time" collaborations rather than programmatic strategies. This happens because internet culture has yet to map itself to the complex social system that powers scholarship and education.

McGann's observation has implications for both consumption and production of digital repositories. Let us focus here on the consumption, and conclude that the adage 'if you build it they will come' is suspect in the case of digital repositories, as it is unclear how prospective users would even know of it, nor how they can evaluate its quality. ${ }^{10}$ In other words, digital repositories are not sufficiently linked to each other. ${ }^{11}$ Moreover, to the extent that such links are created (for example within a repository, listing books that are related to the one the user is currently seeing), a digital context is perceived as unmanageable, ${ }^{12}$ or, in other words, disorganized..$^{13}$ The individual items of a siloed repository thereby become siloed themselves. They are accessed either because the user knows the title beforehand, or because the item contains the keyword that the user was searching for. In comparison to an open stacks library, this precludes

$8 \quad$ McGann, p. 30.

$9 \quad$ McGann, p. 136.

10 Cf. Warwick, C., M.M. Terras, P. Huntington, and N. Pappa. "If You Build It Will They Come? The LAIRAH Study: Quantifying the Use of Online Resources in the Arts and Humanities through Statistical Analysis of User Log Data." pp. 85-102 in Literary and Linguistic Computing 23, no. 1 (2008).

11 Collins, E., and M. Jubb. “How Do Researchers ...", p. 185.

12 Rimmer, J., et al., p. 1384.

13 Jeanneney, J.-N. Google and the Myth of Universal Knowledge: A View from Europe. Translated by T.L. Fagan. Chicago: The University of Chicago Press, 2007, p. $67 \mathrm{ff}$. 
the serendipity of running into works one had not even imagined to look for, the so-called unknown unknowns. ${ }^{14}$

For humanities scholar working with manuscripts, the isolation of digital repositories can be a real problem. Peter Ainsworth, scholar of French studies, finds it a paradox that there is an "absence to date of any new, custom-built or standardised electronic tools to take over the role of the microfilm reader."15 Likewise, Matthew Fisher, scholar of English studies, suggests that such a lack is at the basis for issues of trust and authority in using digital repositories. He imagines that tools and frameworks that can operate and interact between different repositories can solve this. ${ }^{16}$ To make up for this lack and to get on with research, digital assets are approached as though print or manuscript assets. Ryan Szpiech, scholar of Romance languages and literatures, notes that "the academic study of medieval manuscripts has always been undertaken as if in dialogue with printed books, ${ }^{17}$ and Adriaan van der Weel, scholar of book studies, adds that "most of our information habits remain book based."18 And so, as some advantages of digitization are readily admitted, and digital and digitized materials are often used without thinking twice about it, there are also some sharp limitations put on its use, especially when moving from researching (using) to publishing (admitting to use).

The use of material manuscripts, meanwhile, has been substituted largely in favor of digital surrogates. The few scholars who have reflected on the impact of this change in our work have been emphasizing the larger than life quality of digital surrogates. By this I mean that with a digital surrogate, one can

14 A concept that became publicly known after its use by then US Secretary of Defense Donald Rumsfeld, in a briefing on February 12, 2002. Cf. Morris, E. "The Certainty of Donald Rumsfeld." The New York Times. March 25, 2014.

15 Ainsworth, P. "E-Science for Medievalists: Options, Challenges, Solutions and Opportunities." Digital Humanities Quarterly 3, no. 4 (2009).

16 Fisher, M. "Authority, Interoperability, and Digital Medieval Scholarship." pp. 955-964 in Literature Compass 9, no. 12 (2012). The most promising framework, for our fields, is the International Image Interoperability Framework, to be discussed in Chapter Five.

17 Szpiech, R. "Cracking the Code: Reflections on Manuscripts in the Age of Digital Books." pp. 75-100 in Digital Philology: A Journal of Medieval Cultures 3, no. 1 (2014), p. 75.

18 Weel, A.van der. “New Mediums:New Perspectives on Knowledge Production." pp. 253-268 in Text Comparison and Digital Creativity, edited by W. van Peursen, E.D. Thoutenhoofd, and A. van der Weel. Leiden: Brill, 2010, p. 254. 
supposedly "enhance an image's size",19 or, as Maura Nolan, scholar of English literature, puts it, digital surrogates can reveal details otherwise "not visible to the naked eye."20 Indeed, the applicability of the term 'surrogate' has been called into question, since the digital images "will often provide more information than would simple access to the physical object."21 Thus, Ainsworth boasts of digital surrogates at $500 \mathrm{dpi}$ (dots per inch) with each image file being around ${ }_{150 \mathrm{MB}} .^{22}$ The West Semitic Research Project has captured digital photos of Dead Sea scrolls with a resolution so high one can inspect hair follicle patterns and surface deterioration, and made infrared photos to reveal the text more clearly. ${ }^{23}$ The end result of this race for magnification is unsurprising; scholars have already gone as deep as the atomic level. ${ }^{24}$

Digitization on an atomic level should be seen as a reductio ad absurdum of the predilection towards high quality, challenging the whole concept of larger than life digitized manuscripts. It should make us ask how much larger than life digitized manuscripts really are. This has not happened, so far. Instead, digital surrogates are considered outright replacements of the original manuscript. Because of the enthusiasm surrounding the quality of digitized manuscripts, Nollan writes that "digitization [...] offers a new and improved version of the original medieval object." ${ }^{25}$ Szpiech argued that if scholars are under the impression that digitized manuscripts provide a better image than the material manuscript, we will undoubtedly prefer it and more or less forget about the original, material manuscript. ${ }^{26}$ To a large degree, we have indeed, across the different fields working with manuscripts, forgotten about the material manuscript. Even the scholars who have reflected on the relation between material

19 Rimmer, J., et al. “An Examination of the Physical ...", p. 1375.

20 Nolan, M. "Medieval Habit, Modern Sensation: Reading Manuscripts in the Digital Age." pp. 465-476 in The Chaucer Review 47, no. 4 (2013), pp. 470, 472.

21 Crane, G., A. Babeu, D. Bamman, L. Cerrato, and R. Singhal. "Tools for Thinking: ePhilology and Cyberinfrastructure." pp. 16-26 in Working Together or Apart: Promoting the Next Generation of Digital Scholarship. Washington, D.C.: Council on Library and Information Resources, 2009, p. 23.

22 Ainsworth.

23 Hunt, L., M. Lundberg, and B. Zuckerman. "Concrete Abstractions: Ancient Texts as Artifacts and the Future of Their Documentation and Distribution in Their Digital Age." pp. $149^{-172}$ in Text Comparison and Digital Creativity, edited by W. van Peursen, E.D. Thoutenhoofd, and A. van der Weel. Leiden: Brill, 2010, p. 154.

24 "Books Under the Microscope." UT News: The University of Texas at Austin, October 18, 2012; Treharne, E. "Fleshing out the Text: The Transcendent Manuscript in the Digital Age." pp. 465-478 in Postmedieval: A Journal of Medieval Cultural Studies 4, no. 4 (2013), p. 471.

25 Nollan, p. 471.

26 Szpiech, pp. 93-94. 
manuscript and digital surrogate betray a casual identification between the two. One example will, I think, suffice. Ryan Szpiech relates his experience of finding a digitized manuscript on the internet in the following manner: ${ }^{27}$

I follow the first link, and I am off to Portugal, to the library of the Universidade de Coimbra, where there is an extraordinary multilingual manuscript (MS 720) that has, so far, been little studied. With two more clicks I am viewing it in high resolution.

The impression one gets is that Szpiech is treating the screen of his computer as a real, physical window, through which he can look from Michigan where he works, onto Coimbra, specifically, the manuscript MS $720 .{ }^{28}$ Granted, he does say he is looking at it "in high resolution," but this is merely the predilection for high quality at work. More important is that he says that he views "it", meaning the material manuscript, not the digital surrogate. Indeed, at the end of his article when he lists all his sources, he lists the digital surrogate that he looked at as "MS 720, Biblioteca da Universidade de Coimbra, Coimbra." This means that he is citing the material manuscript, which he confirmed he never actually saw (nor touched, smelled, tasted, or heard). Any trace of him having consulted the digitized manuscript is gone, and with it the ability for a critical reader to replicate his editorial and analytical decisions.

To understand why people would do this, I wish to invoke the philosopher Walter Benjamin: ${ }^{29}$

Even the most perfect reproduction of a work of art is lacking in one element: its presence in time and space, its unique existence at the place where it happens to be. [...] The presence of the original is the prerequisite to the concept of authenticity. [...] [T] hat which withers in the age of mechanical reproduction is the aura of the work of art.

In this context, we can consider manuscripts to be works of art, making print publications the reproductions of which he speaks. The thinking laid out here has had an immense influence on humanities scholars. By editing a variety of manuscripts into one printed work, the aura of each manuscript became

27 Szpiech, p. 76.

28 A similar statement is made by Maura Nolan who writes "I can sit in Berkeley, California, and look at a manuscript in Oxford, England, thousands of miles away." Nollan, p. 473.

29 Benjamin, W. "The Work of Art in the Age of Mechanical Reproduction." pp. 217-251 in Illuminations: Essays and Reflections, translated by H. Zohn. New York: Schocken Books, 1969, pp. 220-221. 
lost, as the thinking goes. ${ }^{30}$ This explains the enthusiasm of people for digitized manuscripts, as it brings back some of that aura. Especially when several copies of the same work are brought together, digitized manuscripts can restore the plurality that the manuscript world offered and which the print world took away, Francesco Stella, scholar of medieval Latin literature, argues. ${ }^{31}$ As Farkas Gabor Kiss, scholar of renaissance literature, puts it, using digitized manuscripts can replicate the medieval reading experience. ${ }^{32}$ Or, as Van Peursen puts it, this makes new realizations of 'presence' possible. ${ }^{33}$ Or consider Deborah McGrady, scholar of French literature, who writes that "medieval manuscript readers and modern viewers of the digitized codex [...] share a nostalgic desire for a multi-sensorial and intimate encounter with the textual body." ${ }^{34}$ Especially this last comment by McGrady provides some explanation why reference is made to the material manuscript and not to the digital surrogate, as the aim would be to capture the supposed aura of the material manuscript. A pathological desire to reassert the aura is what Jacques Derrida has called 'archive fever': "a nostalgia for the return to the most archaic place of absolute commencement." 35 With academic libraries restricting access to their manuscript collections more and more, equally due to budgetary restrains as due to conservation concerns, digitizing manuscripts became the path of least resistance to let this fever run its course.

If you think that digitized manuscripts cannot possibly bring back the aura of the original, since it itself is a mechanical reproduction, you are not alone. Evyn Kropf, librarian at the University of Michigan who led an effort to digitize the entire collection of more than a thousand Islamic manuscripts, shows astonishment that some scholars have published on her manuscripts relying

3o See Szpiech's use of 'authentic' to describe manuscripts; Szpiech, pp. 77-78.

31 Stella, F. "Digital Philology, Medieval Texts, and the Corpus of Latin Rhythms, a Digital Edition of Music and Poems." pp. 223-249 in Digital Philology and Medieval Texts, edited by A. Ciula and F. Stella. Pisa: Pacini, 2006, p. 229. He is undoubtedly influenced by Dagenais, J. The Ethics of Reading in Manuscript Culture: Glossing the Libro de Buen Amor. Princeton: Princeton University Press, 1994.

32 Kiss, F.G., and et al. "Old Light on New Media: Medieval Practices in the Digital Age." pp. 16-34 in Digital Philology: A Journal of Medieval Cultures 2, no. 1 (2013), p. 21.

33 Peursen, W. van, p. 8. 'Presence' is the Modern Literature variant of what 'New Philology' is for Philology and the 'Material Turn' is for Anthropology, cf. Gumbrecht, H.U. Production of Presence: What Meaning Cannot Convey. Stanford: Stanford University Press, 2003.

34 McGrady, D. "Textual Bodies, the Digital Surrogate, and Desire: Guillaume de Machaut's Judgment Cycle and His Protean Corpus." pp. 8-27 in Digital Philology: A Journal of Medieval Cultures 5, no. 1 (2016), p. 8.

35 Derrida, J. Archive Fever: A Freudian Impression. Translated by E. Prenowitz. Chicago: The University of Chicago Press, 1996, p. 91. 
entirely on the digital surrogate. ${ }^{36}$ Says Kropf: "Consulting both original and surrogate seems appropriate, as there may be some qualities of the original that a surrogate does not mediate well." ${ }^{37}$ What could these qualities be?

\section{The Intangible Aura of Material Manuscripts}

Consider the following similar statements, apparently written independently:

Taste, smell, and touch tax our ability to describe sensation in language and thereby to communicate the experience of handling a medieval book, which allows aura to maintain its status as a secret. ${ }^{38}$

And:

The manuscript cannot only be seen - it must be touched, smelled, read, received, interpreted in order to be appreciated and understood. It can be appreciated fully only by means of a give-and-take relationship, and in that relationship, it will always remain partly elusive. ${ }^{39}$

And:

Without a multi-sensual embodied experience of the material artifact, we experience only the transcendent, the partial; and we only ever grasp a fragmented and limiting understanding of the book's intrinsic aura. ${ }^{40}$

These statements come from Maura Nolan, Ryan Szpiech, and Elaine Treharne, ${ }^{41}$ and all speak of using a manuscript as a bi-directional contact that involves not

36 Kropf, E.C., "Will that Surrogate Do?: Reflections on Material Manuscript Literacy in the Digital Environment from Islamic Manuscripts at the University of Michigan Library," pp. 52-70 in Manuscript Studies vol. 1, no. 1 (2017): p. 67. Cf. Arnold, D. "Digital Artefacts: Possibilities and Purpose." pp. 159-70 in The Virtual Representation of the Past, edited by M. Greengrass and L. Hughes. Farnham: Ashgate, 2008, p. 159; Correa, D.J. "Digitization: Does It Always Improve Access to Rare Books and Special Collections?" pp. 177-79 in Digital Technology \& Culture 45, no. 4 (2017), p. 177.

$37 \quad$ Kropf, p. 54 .

$38 \quad$ Nolan, p. 476.

39 Szpiech, p. 90.

40 Treharne, p. 477.

41 There are more scholars who support this view, see: Peursen, W. van, p. 9; Rimmer et al., p. 1376; Terras, M.M. "Artefacts and Errors: Acknowledging Issues of Representation in 
only all five senses but also our internal capacity to interpret and communicate the holistic experience that emerges from this contact. Further, they both emphasize that even then something of that aura that is created (or experienced) at contact remains unknown or ineffable.

Nolan seeks this ineffability in the magical. She concludes that "these quasireligious aspects of manuscript study imbue books with the magic of the past."42 It may feel that way, but not because of the manuscript. I wish to suggest that it can be largely a projection of our own experience onto the manuscript. Every manuscript was at one point new and could therefore not possibly invoke the past. Furthermore, I suspect that the 'magic' Nolan experiences is largely dependent on modern-day library conditions. Such manuscripts can only be seen by appointment, in a designated room in which you may only enter after stowing your bag. Pens are strictly prohibited. Manuscripts usually come in a cardboard box and need to be laid down on a pillow with lead snakes to keep the manuscript open. You are surrounded by silent people, each working on another ancient artifact. All these aspects make reading a manuscript a very special, unusual thing to do. And all these aspects are foreign to how people used manuscripts in centuries before. Pre-modern people had manuscripts in their own possession and used them intensively. One of the most normal things to do while actively reading was to write notes in the margin. Go ahead and try to write a gloss in the margin of a manuscript next time you are at the library; see how far you will get before librarians come rushing from every side. So in this sense what we experience with a manuscript is not essential to the manuscript itself, but created ('performed' if you will) by our current context.

Szpiech does not specifically address the elusiveness of manuscripts but he hints at an interpretation worked out more fully by Treharne. She makes an excellent point about the difficulty of judging the size, weight, use state, and material costs through inspection of a digital surrogate, ${ }^{43}$ but it is another thing to say that "this hapticity is essential." ${ }^{44}$ To argue for that, she writes that: "With a medieval book, the fortunate momentary owner touches, skinupon-skin, in direct tactile intimacy with the very people who compiled and wrote those books." ${ }^{25}$ In this interpretation, the contact between manuscript and reader is made out to be almost sensual, skins rubbing against each other

the Digital Imagining of Ancient Texts." pp. 43-61 in Kodikologie Und Paläographie Im Digitalen Zeitalter 2, edited by F. Fischer, Chr. Fritze, and G. Vogeler. Norderstedt: BoD, 2010, p. 55; McGrady, p. 9.

42 Nolan, p. 475 .

43 Treharne, p. 476.

44 Treharne, p. 471.

45 Treharne, p. 474. 
creating an intimate encounter. Nobody would disagree with Treharne when she says that "little of this intimacy and involvement, this prosthetic function, can be represented in the digitized image of a manuscript." 46 After all, only visual aspects are represented in a digital surrogate, and even then in a mediated manner, converting a three-dimensional perception to a two-dimensional one, possibly distorting the size and color of the original object. ${ }^{47}$ Even when we use a touch screen we are always one step removed from the object. ${ }^{48}$ Many scholars will remember the little moments of admiration when, for example, you find a smudge of a fingerprint in the margin of a medieval manuscript, or some ancient hair stuck in between pages. Equally, good materials like ink, paper, and leather can certainly be appreciated by codicologists. But these are tiny moments in between the real work and are accidental to it, not essential.

To be more precise, I have argued that using digitized manuscripts is a different experience from using material manuscripts in modern libraries, which is a different experience from how manuscripts were used historically. There are two conclusions to be drawn from this. Firstly, even though using digitized manuscripts will not get you the same experience as using a material manuscript, so is using a manuscript of hundreds of years old in a university library not the same as using a manuscript of just a few years old in your private possession. I therefore deny claims that this aural, ineffable experience of handling a real manuscript is "clearly paramount" (Treharne) or "essential" (Nolan). Secondly, it is not like using digitized manuscripts will get you none or only a shadow of the experience you would get from handling the real artifact. Rather, you simply get another experience. Since we established that such an experience is constituted by the contextual performance of handling a manuscript, each experience (all three) are equally valid.

I therefore conclude that discussions on the relationship between digitized and material manuscripts have brought us little to nothing. It is neither correct to see digitized manuscripts as better than their material counterparts, nor is it correct to see them as worse than them. The root problem for both mistaken interpretations is that the 'digital materiality' of digitized manuscript is not

\footnotetext{
46 Treharne, p. 474.

47 This reduced experience has upset some people so much that they spent considerable efforts to salvage it, see e.g. Chu, Y., D. Bainbridge, M. Jones, and I. Witten. "Realistic Books: A Bizarre Homage to an Obsolete Medium?" pp. 78-86 in Proceedings of the 4th ACM/ IEEE-CS Joint Conference on Digital Libraries, New York: ACM, 2004.

48 Mangen, A. "Hypertext Fiction Reading: Haptics and Immersion." pp. 404-19 in Journal of Research in Reading 31, no. 4 (2008), p. 405.
} 
understood. ${ }^{49}$ We would only need to consider how extraordinarily specific technical guidelines for capturing manuscript materials and print publications are, ${ }^{50}$ to make us realize not all digital surrogates are created equal. Such standards are necessary, since, as Mats Dahlström sums up: ${ }^{51}$

digitisation and the subsequent editing of images has perhaps more than any other editing phase made us attentive to the fact that virtually all parameters in the process (image size, colour, granularity, bleed-through, contrast, layers, resolution etc.) require intellectual, critical choices, interpretation, and manipulation.

If the producers of digital surrogates are aware of the influence technical decisions have on the outcome, so should we as consumers. How do we assess the quality of digital surrogates? The only scholar who has identified this question, that I am aware of, is Melissa Terras, scholar of digital humanities. In search for an answer she is a bit helpless. She timidly concludes that "it can be difficult to assess the quality of digital images," and puts the onus back on the producers of digital surrogates, arguing that "it is imperative that those undertaking digitisation programs consult guidelines and carry out benchmarking procedures to ensure quality control of the digitised output." 52 This, to me, is unacceptable. We cannot hold our libraries accountable for mistakes we make based on digital surrogates. Besides, the discussion on how to properly digitize has already played out for the most part, and with hundreds of thousands of manuscripts already digitized there is little we can do in influencing their quality. Instead, we should simply acknowledge the digital materiality of digitized manuscripts, appreciate the added value they bring, and work around their drawbacks. This, we cannot do as long as we are incapable of describing their digital materiality.

49 For a similar discussion on art and museum pieces, see Cameron, F. "Beyond the Cult of the Replicant: Museums and Historical Digital Objects—Traditional Concerns, New Discourses." pp. 49-75 in Theorizing Digital Cultural Heritage: A Critical Discourse, edited by F. Cameron and S. Kenderdine. Cambridge Mass.: The MIT Press, 2007.

$50 \quad$ See e.g. "Technical Guidelines for Digitizing Cultural Heritage Materials." Federal Agencies Digital Guidelines Initiative, 2016; Dormolen, H. van. Richtlijnen Preservation Imaging Metamorfoze. Den Haag: Koninklijke Bibliotheek, 2012.

51 Dahlström, M. "Critical Editing and Critical Digitisation." pp. 79-98 in Text Comparison and Digital Creativity, edited by W. van Peursen, E.D. Thoutenhoofd, and A. van der Weel. Leiden: Brill, 2010, p. 81.

$5^{2}$ Terras, p. 52. The difficulty of assessment had been noted in circles of production, cf. Lynch, C. "Authenticity and Integrity in the Digital Environment: An Exploratory Analysis of the Central Role of Trust." pp. $3^{2-50}$ in Authenticity in a Digital Environment. Washington: Council on Library and Information Resources, 2000, p. 35. 
I have come to see this question as relating to two factors: the digital data that constitute the actual, digitized manuscript, and the digital context in which this is stored or offered. The first is one or more files, for example a folder full of image files, or a PDF with a photo on each page, or a combination thereof, for example when different qualities are offered. The second can take on many shapes but I shall call it in all cases a repository. This context can be as rudimentary as a collection of folders on your own computer, in which case we should look at the folder structure and file naming to evaluate the repository. It can also be as advanced as a web server hosted by a library, that dynamically serves up manuscripts through an interface that is enriched with catalog data. Ten notions can help us to analyze those two factors: (1) size of the collection; (2) online availability; (3) ability to download; (4) the portal; (5) the viewer; (6) indication of page numbers; (7) image resolution; (8) color balance; (9) lighting; and 10) how the image is cut.

The size of the digital repository (relative to the number of material manuscripts held) is an important way to assess the commitment a library has to digitization and understand the trajectory of digitization globally. Whereas in 2011 libraries with Islamic manuscripts would boast of two digit numbers of digitized manuscripts, ${ }^{53}$ the most important ones have now scaled to four digit numbers and beyond. In a good number of cases, libraries adopted a strategy of blanket digitization, simply digitizing a whole collection without picking out the supposed important manuscripts and leaving out supposedly unimportant ones. Other libraries hold the policy that the first request pays. Whoever asks for a holding to be digitized will pay a fee for it, subsequently it can be accessed for free by anyone else. This ought to be preferable over another popular policy, namely to digitize as a project based on external funding. I have observed that several repositories started showing decay after this funding period was over. We shall see examples of this in the next chapter. In this regard, size is important for another reason, namely the hope that larger repositories will be more likely to receive continued funding, maintenance, and upgrading.

Online availability is, I think, quite crucial for any philologist, as it takes out expensive and time consuming travel to faraway libraries. However, users need to be aware that not everything can be instantly seen online. In cases in which digitized manuscripts are not offered on a website, their files need to be requested and usually the files will still be send over the internet. In other

53 Cf. Swanick, S., "Of making books there is no end: Islamic manuscripts on the Web," pp. 416-419 in College and Research Libraries News (July/August 2011). 
cases, digitized manuscripts are behind paywalls. This means you cannot see anything unless you pay first, after which you have online access to all the files. Of the twenty repositories I compare in the next chapter, the vast majority allow free, online access.

Such access does not always translate in the ability to download. Some repositories only allow online viewing and have implemented technological hurdles to impede users from downloading. Other repositories will add a watermark to every picture, making some readings more difficult and browsing more annoying. Others, again, only allow users to download one page at a time. Only about a third of the repositories I looked into allow full download. I think it is important to keep private copies of the manuscripts you work with on your own computer. This will ensure you can access them again, and will allow you flexibility in annotating them while you are working. In addition, if you intend to refer to manuscripts in publications, you may be asked by readers to provide your evidence so that they can double-check your analysis, which will be easier to do if you have the files in your possession. Related to this aspect of downloading is the copyright asserted over digital surrogates. This is discussed in further detail in the next chapter.

Another aspect to consider is the portal, which is the website which the user first enters, in order to find from there the actual photos of a manuscript. It is usually related to the manuscript catalog which a library has. In my own field of Islamic studies, the portal is usually very simple. This is definitely an area in which repositories can be expected to improve, allowing for new ways of browsing that go beyond a traditional catalog. 54

The viewer is the technology used to allow users to see and browse the digitized manuscript. For close reading I find it better to download the manuscript and inspect it on my own. For quick browsing and skimming, however, the online viewer is a welcome technology. Here, too, improvement may be expected. Currently, most viewers are somewhat clunky, especially in browsing from page to page. Using technology makes sense insofar as it is helping us. When it works against us, which is the case for the majority of viewers in Islamic studies, we need to proceed with caution.

Page numbers (or folio numbers), together with the manuscript call number, are the basic descriptions that a user needs to make a reference to a

54 Cf. Chevallier, P., L. Rioust, and L. Bouvier-Ajam. "Consultation of Manuscripts Online: A Qualitative Study of Three Potential User Categories." Digital Medievalist 8 (2013); Ornato, E. "La Numérisation Du Patrimoine Livresque Médiéval: Avancée Décisive Ou Miroir Aux Alouettes?" pp. 85-115 in Kodikologie Und Paläographie Im Digitalen Zeitalter 2, edited by F. Fischer, Chr. Fritze, and G. Vogeler. Norderstedt: BoD, 2010, p. 96. 
manuscript. In many cases, the viewer gives a wrong page number or none at all. Thus, the user is left to look at the folio numbers in pencil, as far as it exists in a manuscript and as far as it can be seen on a photo. It would be great if upon downloading the manuscript call number and page number could automatically be embedded in the file, for example hard coded in the bottom left corner and in the file name. In lieu of this, I would advise users to make sure to rename any downloaded file according to the provenance, including library or city name, manuscript number, and folio number. You may also find it helpful to rename the folder in which the file reside to indicate title, author, and manuscript number.

The image resolution is the most important metric in determining the quality and usability of a digital surrogate. Technically we are looking for the DPI or PPI: dots/pixels per inch, which tells you how many pixels were spent on storing one square inch of material manuscript. The higher the better, obviously, although it can take proportions that are unmanageable for private use. For example, the higher it gets, the higher the file size, which complicates downloading and storing. Also, very large images cannot be opened with any image viewer; simple ones will crash. The problem with DPI is that it cannot always be ascertained, or rather, it should always be doubted when not coming straight from your own camera. This is because images can and likely will be processed before they reach you, meaning that some software touched it and perhaps compressed it, reformatted it, or possibly enlarged it (without, obviously, any gain in quality). In this process, the metadata for DPI might have been altered or deleted. D P can still be a useful measure when filing a specific digitization request with libraries or museums. Advice on this depends on your needs, but it is good to know that 300 is what is used in print media (magazines, newspapers and the like).

For any images we encounter, we do well to evaluate images with a combination of three indicators: dimensions, file size, and a visual impression. For example, the digital surrogate for Landberg MSs 711 folio 150a, at Beinecke Library, is said to be available in "high resolution." Its downloadable JPG file is $2588 \times 3415$ pixels. Had it been stored in a format called "lossless JPG," a variant of the JPG format that preserves the quality of the image as much as possible, this image should weigh around $13.3 \mathrm{MB},{ }^{55}$ however, the size of the downloadable file is actually $2,3 \mathrm{MB}$, more than eighty percent smaller than expected. In

55 JPG file size is different from image to image, as even the lossless format performs file size compression techniques, see Murray, J.D., and W. VanRyper. Encyclopedia of Graphic File Formats. 2nd ed. Bonn: O’Reilly \& Associates, 1996, pp. 191-205. 
other words, some compression was applied to the image. This proves that not only image dimensions should be used to get a metric for the image quality. I should point out, though, that Beinecke in fact supplies fairly high quality images, as a visual inspection will quickly tell. Take for example images from McGill. The digital surrogate for Osler MS 389/23, folio $1 b$ measures $4396 \times 6116$ pixels. It is therefore much larger in dimensions than Beinecke's image, yet the image from McGill only has a file size of $1,1 \mathrm{MB}$, much smaller than Yale. Even so, McGill's images are usable. Take the images from the Parliamentary Library (Majlis) in Tehran as an example. Images of MS 5808 are approximately $650 \times$ 1270 and have a file size of approximately $370 \mathrm{~KB}$. For reading purposes, this is not good enough. The resolution is so low, that here we should remind ourselves of Terras's fear that we cannot trust the readings from images that do not help us but rather work against us, in deciphering the manuscript.

In addition, a visual assessment is necessary. For example, Leiden University has given Brill publishers the rights to exploit digital surrogates of Islamic manuscripts. From the file size and dimensions one would not expect anything strange, but a visual assessment reveals that there is a peculiar jaggedness to the text, which severely reduces the quality in comparison to excellent resolutions such as the BnF offers through Gallica. Most of the repositories considered in the next chapter, however, offer resolutions that we can work with. Only in rare cases do we encounter digital surrogates for which the use for philological purposes is highly suspect.

The usability is not only influenced by the resolution. Also color balance plays a role. ${ }^{56}$ What is meant by this is how true to color the digital surrogates are compared to the original object. This is hard to judge when we do not have the material manuscript to compare it with, but some tricks might give us a clue. If a repository offers different qualities of the same manuscript we can compare these different qualities. ${ }^{57}$ If we have photos of more than one manuscript we can compare them. If they are strangely different, we know that the color balance is off for at least one of these photos. We can also look for

$5^{6}$ Says Julia Craig-McFeely, historian of medieval music: "colour is one of the most devastatingly misleading fields in the digital imaging world." Cf. Craig-McFeely, J. "Finding What You Need, and Knowing What You Can Find: Digital Tools for Palaeographers in Musicology and Beyond." pp. 307-39 in Kodikologie Und Paläographie Im Digitalen Zeitalter 2, edited by F. Fischer, Chr. Fritze, and G. Vogeler. Norderstedt: BoD, 2010, p. 312.

57 For example, from Beinecke Library I got two different files for MS Landberg 335, folio $1 \mathrm{~b}-2 \mathrm{a}$, one at $27 \mathrm{~kb}$ with dimensions of $1200 \times 908$, the other at $1.6 \mathrm{mb}$ with dimensions of $3463 \times 2620$. The small file shows distinctly more red, given the page an earth tone, while the big file shows the page as more yellowish color. 
common mistakes. These include that the paper looks green or blue or where we expect black and red ink we may see the ink color shift. Other issues are included in color balance as well, most notable the issue when the text of the back side of the folio is bleeding through on a photo. Especially this last issue can impact readability significantly. Color balance might simply interfere as a factor of annoyance. This is, I think, not to be brushed aside. When performing a close reading, you wish there to be as little distractions as possible and a severely skewed color can be such a distraction.

Much more of a distraction is the lighting. To make a photo, there obviously needs to be a light source. Ideally, the studio is brightly and evenly lit, giving the manuscript an even, bright lighting, resulting in a vibrant, sharp photo. This is not always the messy reality that we will encounter. Sometimes there is uneven lighting across different pages, giving a restless impression while browsing, as one needs to adapt to the different light intensity of each page. Sometimes valleys of shadow and hills of over-exposure are present. This means that parts of one page turn darker, while other parts turn brighter in the image without this being true for the material manuscript. This can happen when the page was not fully flat when the photo was taken, with the bulge of the paper creating these shadows, and it is a significant factor influencing the ability to read the text. Shadow and over-exposure can also occur when the photographers did not use a professional light source, with light coming clearly from a specific angle. In this case, especially, gilded parts of the manuscript can light up to the extend that they become unreadable. Something similar happens when a manuscript uses glossy paper, as some areas can bounce back so much light as to white out text in those parts. This happens especially at the top of the bulge of a page, if not flattened. Lastly, as far as I have come across, when manuscripts have been repaired using tape, a direct light source will invariably cause those parts to white out. In short, then, lighting can hamper readability (and hence, reliability) of a digitized manuscript and is a major cause for restless, uneven experience of the mise-en-page.

The last aspect that I found useful to consider is what I call the cut. This refers to the decision as to what is part of the photo and what falls just outside of it. A great cut means that the photo reveals a little space around the edge of the page and the cover, so as to assure a user that no visual aspect of the manuscript is hidden. Some repositories have cut their photos too tight. Their decision was to cut around the text block, leaving the edges of the page unaccounted for. For philologists this can be problematic when marginalia are important to consider, as there is the danger that parts of the marginalia are invisible. I am happy to notice that for the vast majority of digital Islamic manuscripts, the cut is not too tight. 


\section{$5 \quad$ New Habits for Philologists in a Digital World}

Digitized manuscripts are a godsend for philologists, as they solve a problem we newly encounter. In the digital world we now work in, we usually approach pre-modern texts through the funnel of the print world, as it is printed materials that are converted to digital texts. Furthermore, whereas in the print world we frequently have the option of several editions, some of them with critical apparatus, in the digital world this is usually lost as only one edition is converted to digital text, usually without the apparatus, and even if multiple editions are available, we do not have convenient means to automatically iterate over all of them to spot meaningful differences. For distant reading, for example trawling big text corpora for finding larger trends, this does not need to be a great problem. However, if what we want is a close reading and we want to truly understand what an author is saying, this becomes a great issue. Being able to go back to the material evidence that manuscripts offer, by means of a digital surrogate, is therefore something that we will likely make use of more and more, to fully understand the text we are investigating.

If you are a philologist yourself you will probably need no convincing of this, but here is one example for those who are not entirely sure if this is such a problem. Take the legal ruling that the medieval theologian Ibn Taymiyya gave on whether Muslims could live in the city of Mardin (in the East of presentday Turkey) or should emigrate elsewhere since the city was not under Muslim rule. At first his answer seems nuanced and subtle, arguing for a compromise solution in which emigration is favored but not obligatory. But then the conclusion of the ruling puts all of this in an entirely different light: "[Mardin] is of a third type in which the Muslim should be treated as he merits, but the one outside of the Law (shari $a$ ) of Islam should be combatted as he merits." ${ }^{.5}$ The different verbs, "be treated" (yu'ämal) and "be combatted" (yuqātal), make an especial impact since the two sentences are constructed exactly the same. Like this it was printed in 1909 and from then on reprinted up until today. It has been quoted in this form by many leaders of terrorist groups, ${ }^{59}$ and has found its way online and in a scholarly digital text corpus. ${ }^{60}$ And yet it was pointed out by the Mauritanian scholar Abdullah bin Bayah that this should be

$5^{8}$ Yahya Michot offers a slightly different translation: "Rather, [Mardin] constitutes a third type [of domain], in which the Muslim shall be treated as he merits, and in which the one who departs from the Way/Law of Islam shall be combated as he merits." See Michot, Y. Muslims under Non-Muslim Rule. Oxford: Interface Publications, 2006, p. 65.

59 See Michot, Muslims under Non-Muslim Rule, pp. 1oiff.

6o I mean the Open Islamic Texts Initiative, which relies for this text on the digital text corpus al-Maktaba al-Shāmila. See Miller, M.T., M.G. Romanov, and S.B. Savant. "Digitizing 
considered a misprint and that we should read "be treated" (yu'ammal) in both cases. ${ }^{61}$ Among the evidence he brings forth is one of the earliest manuscripts of Ibn Taymiyya's text, which indeed shows yu'ämal, not yuqātal. ${ }^{62}$ It is evident, then, that establishing what the text is can be of literal vital importance.

The barrier to cross-check digital documents and print publications with manuscripts is getting lower and lower, as more manuscripts are available through digital surrogates. No doubt, we will therefore see a resurgence of manuscript studies. But as much as the higher usage of manuscript evidence is to be celebrated, we should be aware that digital surrogates cannot be used indiscriminately. Any digital resource of interest should be evaluated, which we can do according to the ten aspects that I outlined above: (1) size of the collection; (2) online availability; (3) ability to download; (4) the portal; (5) the viewer; (6) indication of page numbers; (7) image resolution; (8) color balance; (9) lighting; and (10) how the image is cut. Evaluating these aspects can answer the question to what extent the technology is working for you, rather than against you. This should be our leading principle in implementing digital photos in our philological work. The unfortunate result is that many resources cannot be used for any and all purpose. Many low resolution digital scans of microfilms exist. These are surrogates of surrogates. They can still be (and are) profitably used, for example to corroborate a particular reading. I am however skeptical of using them as a single source for making an edition. Perhaps, indeed, $99 \%$ of a manuscript can still be deciphered by using them, but it is about that $1 \%$ of cases in which the scribe fumbled a bit with his pen and it is unclear what the word reads. In those $1 \%$ cases, you do not wish to have a low-resolution, black and white reproduction of a reproduction as your sole witness. Even if you are steeped in the subject and can make an educated guess towards the correct reading, I think it is simply the duty of a scholar to concede that this is not a reliable way of working.

The effect stacks; if we have bad digital photos, we end up with bad editions, leading to bad translations, resulting in bad analyses. For many fields in the humanities, manuscripts remain the foundation of our work. So let us make this foundation as strong as we can. Our resources are limited and the number of manuscripts to be potentially digitized is incredibly large, so we can realistically only digitize things once. We have one chance to do it right,

the Textual Heritage of the Premodern Islamicate World: Principles and Plans." pp. 103109 in International Journal of Middle East Studies 50, no. 1 (2018).

61 Michot, Y. "Ibn Taymiyya's 'New Mardin Fatwa'. Is Genetically Modified Islam (GMI) Carcinogenic?" pp. 130-181 in The Muslim World 101, no. 2 (2011), p. 145.

Michot, “Ibn Taymiyya's 'New Mardin Fatwa," p. 146. 
with an eye towards long term preservation and perhaps innovations such as automatically recognizing text within manuscripts. For resources yet to be digitized, this is something we ought to give our input on to the digitization experts in libraries and museums. For resources that are already digitized, the same principles applies: we can realistically only once critically edit a work, so let us get it right that first time. This means we should not use faulty digital surrogates that do not enable us to do our work but in fact hinder it. If that is all we have, we should rather chose to not edit it at this point in time than to go ahead and make our edition rely on poor digital surrogates. You may be thinking right now: "I am not aware of any published documentary material that has been read erroneously (and published, and refuted) due to faults in the digitization process." ${ }^{33}$ This I find a maliciously ignorant stance towards the digital materiality of digitized manuscripts. We know that digitization can be of very high quality, but in the vast majority of cases is far from it. We also noticed that Ryan Szpiech did not disclose in his bibliography that he used the digital surrogate, instead citing the material manuscript as his source, and he is hardly alone in this practice. Misreads because of faults in the digital materiality of the surrogate are bound to happen, but if we do not tell our readers we made use of a digital surrogate, nobody will be able to call us out on it.

If, however, the quality of the photos checks out, I do not see serious objections to using exclusively digital surrogates in establishing a critical edition. For the classical work of editing a main text, concentrating on the text block, photos are frequently sufficient to establish the correct reading. It is, however, only fair that we do not let readers make the mistaken assumption we had access to the material manuscript. Being honest about this means that we should refer to the surrogate in our bibliography and we should include a description of the digital materiality of the photos, for example in the codicological description of the manuscript. This description need not be long, it can in fact be one sentence. In my own work I have used a sentence like this:

The digital images I work with are $2051 \times 1925$ showing two pages, at about $500 k b$. The cut is tight and color balance is fine. ${ }^{64}$

This sentence conveys that I was using digital surrogates rather than the original manuscript. Then I described the general level of detail by combining the image dimensions and the file size, and mentioning whether one or two pages

63 Terras, p. 56 .

64 Lit, L.W.C. van. The World of Image in Islamic Philosophy. Edinburgh: Edinburgh University Press, 2017, p. 257. 
are visible. I then specified if the borders are visible or if information on the edge of the manuscript could fall outside the photos. I then mentioned if the photo is true to the actual color. These bits of information together give a sense of how legible a digitized manuscript is, and how professional the digitization was done. This, in turn, gives the reader a basis to judge how accurate the edition can be. In this case, the reader may notice that the images are not that great. It could be that some information in the margins of the manuscript is missing or not entirely legible due to the cut, and the file size is a bit small, as in my experience $\mathrm{IMB}$ per page spread is generally a more reasonable file size. You can add to this description a note whether you had access to the material manuscript, and if so, what the purpose was of handling the manuscript itself, for example, in order to verify certain ambiguous readings. A description of the repository can also be included, based on aspects one through six, depending on how unusual these aspects are.

With that, we have come to a close of this chapter. Clearly, digital surrogates serve a very important function in our current workflow and are likely only to grow in their importance. Using digitized manuscripts can help us reach a more authentic reading of a text in a faster and cheaper fashion and has the potential to answer entirely new research questions. How problematic it is that this reduces our engagement to the sense of sight, at the cost of losing the rich mix of the other four senses, is something that we can evaluate on a case by case basis. Neither should we think that digitized manuscripts are a neutral window onto the material manuscript and we would be therefore fooling our readers were we to cite the material manuscript when we in fact consulted its digital surrogate. We can get a better grip on the usability of a digitized manuscript by evaluating it according to the ten categories introduced above and, in fact, we can use these to include a digital codicological description in our publications. A leading question we should ask is: is the digital surrogate helping me or hindering me, in doing my work? If the latter, we might have to make the hard decision of not going through with our work. What kind of variety in digitization you might reasonably expect to encounter is the topic of the next chapter. 